\title{
Developing tools to promote culturally competent compassion, courage, and intercultural communication in healthcare
}

\author{
Irena Papadopoulos*, Sue Shea, Georgina Taylor, Alfonso Pezzella and Laura Foley
}

\begin{abstract}
Background: Compassion is an important concept in healthcare, and in addition, care should be delivered in a culturally competent manner, taking into account the values, culture, and health beliefs of the individual. However, the training of nurses and other healthcare professionals may not adequately equip them to practice in a manner which is both compassionate and culturally competent. In this paper, we report on the development of three learning tools, designed to promote the skills and strengthen the capacity of nurses and healthcare professionals to provide culturally competent and compassionate care.

Methods: The project involved the participation of six European countries in the development of three learning tools, covering culturally competent compassion, culturally competent courage, and intercultural communication. The principles which informed the methodology derive from the previous work on the Papadopoulos, Tilki and Taylor (PTT) model of transcultural nursing and cultural competence, and were also informed by the Intercultural Education of Nurses in Europe (IENE1 \& IENE2) projects. Each partner country was required to produce one tool for each topic area, based on guidance provided by the project co-ordinator, leading to the development of eighteen tools in total. The tools were administered mainly to student nurses to test their feasibility.
\end{abstract}

Results: The emerging tools contained important theoretical and practical components, whereby innovative learning methods and case studies were included. Student nurses enjoyed using the tools, and enjoyed their flexibility. The learning tools enabled students to become stimulated and to engage together leading to a positive learning experience.

Discussion: The tools allow for a positive learning experience and reflection of good practice to take place. The flexibility and content of the tools allows for them to be of equal value to other healthcare professionals as well as nursing staff.

Conclusion: The tools were initially utilised mainly with student nurses and were received with a positive response. Work is now in place to further implement the tools and evaluate the longer term effects among a range of healthcare professionals and service user health outcomes.

Keywords: Compassion, Culturally competent compassion, Learning tools

\footnotetext{
* Correspondence: R.Papadopoulos@mdx.ac.uk

Research Centre for Transcultural Studies in Health, Middlesex University,

London, UK
} 


\section{Background}

'Compassionate Care' within the healthcare setting has received much attention globally, following concerns that healthcare often fails at a fundamental level, and work is in place at a multidisciplinary level to utilize and integrate this concept $[1,2]$. The role and importance of a compassionate approach was particularly brought to the forefront in the UK, with the release of the Francis Report [3]. This report, which gained international attention, was based on an inquiry into devastating events at Mid-Staffordshire Hospital demonstrating that for many patients the most basic elements of care were neglected.

A frequently used definition of compassion is sensitivity to the pain or suffering of another, coupled with a deep desire to alleviate that suffering $[4,5]$. Compassion, having long associations with most major religions and philosophies, is thought to include a number of virtues, such as empathy, sympathy, kindness, respect, and perhaps most importantly, actually taking some kind of 'action'.

As a rapidly developing field, compassion is potentially crucial to healthcare. There is a growing evidence to suggest that a compassionate approach changes the brain's response to stress and increases pain tolerance [1]. Furthermore, studies show that compassion can assist in .prompting fast recovery from acute illness, enhancing the management of chronic illness, and relieving anxiety. Physiological benefits of compassion have also been reported in studies which show that kindness and touch alter the heart rhythm and brain function in both the person providing compassion and the person receiving it [6-8]. In addition, Cole-King and Gilbert [9] draw attention to the fact that scientific understanding of such relationships and their profound physiological effects ought to make compassionate care a more central concern in medical and nursing training and practice.

Care deliverance in any healthcare setting, should be administered with compassion, but it is also important to ensure that this is delivered in a culturally competent manner, taking into account the values, culture, and health beliefs of the individual.

Healthcare professionals in many large cities across the world work with people from a range of different cultures and backgrounds, which highlights the need for them to not only have an understanding of cultural differences, but to also be aware of how to communicate competently with people from different cultures. In many cases, staff themselves will be culturally diverse, and will have their own cultural values that may influence decisions and behaviours [10]. Etowa et al. [11], in reporting on an increasingly diverse population in Canada, state that a culturally diverse nursing workforce is essential, and that recruitment and retention of nursing students representing diverse backgrounds is vital to the development of a diversified work force [11].

Cultural competency (the ability to respond effectively to people from different cultures and backgrounds) can assist healthcare professionals in the delivery of services that meet the cultural and communication needs of patients. Cultural competency is crucial for high quality, patient-centered care. According to the Institute of Medicine's report: 'Unequal Treatment Confronting Racial and Ethnic Disparities in Healthcare', research consistently indicates that a lack of culturally competent care directly contributes to poor patient outcomes and health disparities. In addition, the deliverance of culturally competent care is thought to increase job satisfaction and staff retention [12].

As Papadopoulos [13] states, the capacity to provide effective and compassionate healthcare requires consideration of peoples' cultural beliefs, behaviours and needs. Valuing patients, as individuals, treating them with compassion, ensuring no person is discriminated against and ensuring equality is also referred to in a number of UK and European documents [14, 15].

As such, Papadopoulos [16] defines culturally competent compassion as:

\section{'a human quality of understanding the suffering of others and wanting to do something about it using culturally appropriate and acceptable nursing interventions. This takes into consideration both the patients' and the carers' cultural backgrounds as well as the context in which care is given'.}

According to Papadopoulos [17], culturally competent compassion is not something we are born with although neuroscientists have recently discovered that our brains have the capacity for developing it. Imaginative teaching methods, good textbooks, good role models and opportunities to practice what one learns under supervision is required to activate our capacity for compassion and nurture compassion in order to re-establish itself as the essence of nursing. Nursing education in particular needs to redress the growing evidence and criticisms that compassion in nursing is often an aspiration and not a true reflection of practice.

However, debate as to whether or not compassion can be taught has existed for some time, and as far back as 1983, Pence [18] raised this question in a well-cited essay, utilizing the differing views of ancient philosophers. Pence (1983) drew on the opinions of Socrates (who claimed that virtues cannot be taught), and Protagoras (who claimed that everyone teaches virtues), concluding that compassion can be taught if medical/nursing education systems reward this virtue alongside other caring virtues, thus ensuring its sustainability. Whilst there is still some debate 
as to whether the concept of compassion can be taught, utilizing a conceptual model/framework on which both practical and theoretical activities can be based, may provide a clear opportunity for learning and sustaining the concepts of culturally competent compassion, courage, and communication within the healthcare setting.

Intercultural education promotes the understanding of different people and cultures. It respects the identity of the learner through the provision of culturally appropriate and responsive quality education. It provides learners with cultural knowledge, skills and attitudes to enable them to respond to others with respect, compassion, and understanding. This may include teachings that accept and respect the normality of diversity in all areas of life, together with efforts to sensitize learners to the notion that we naturally develop in different ways. Such education may assist in the transformation of the individual and the institution and also operate as a mechanism for the transformation of society. http://ien.inclusion.msu.edu/node/130

Helping learners to become culturally competent and compassionate practitioners remains a major challenge for nursing education [19]. Culturally competent and compassionate care is not only morally and financially essential, but it is required in many countries through national legislation and/or national health policy as well as EU policy as already stated above.

With this important fact in mind, Papadopoulos and colleagues have developed a model, which formed the basis of a European funded project (Leonardo Da Vinci Life Long Learning programme). The project aimed to promote the skills and strengthen the capacity of nurses and healthcare professionals to provide culturally competent and compassionate care to patients as well as facilitate their effective participation in the European labour market.

In this paper we focus on the development of a set of learning tools (IENE 3 Tools) aimed at promoting culturally competent compassion, courage and intercultural communication.

\section{Methods}

This project, referred to as 'Intercultural Education of Nurses in Europe 3' (IENE 3), involved the participation of six European countries (United Kingdom, Romania, Italy, The Netherlands, Germany and Turkey) in the development of three learning tools (IENE3 Tools), covering the following topic areas of intercultural education:

Tool 1 - Culturally competent compassion (as defined above)

Tool 2 - Culturally competent courage (a virtue which enables us to do the right thing for the people we care for, to speak up when we have concerns and to have the personal strength and vision to innovate and to embrace new ways of working' (NHS Commissioning Board, 2012, p13))

Tool 3 - Intercultural Communication (communication across cultures and social groups. This involves the understanding of different cultures, languages and customs of people from different cultural backgrounds (Wikipedia))

The decision to develop the tools was a pragmatic one, based on the identified need to include the topics covered in the tools within the nursing curricula, yet also be cognisant of the lack of accessible user-friendly materials. The development of the tools was informed by a theoretical stance that can probably be described as being between a constructivist and connectivist theory of learning. We are committed to the principles of constructivism as espoused by Bruner [20] and Vygotsky [21] with a strong belief that people construct their own understanding and knowledge of the world, through experiencing things and reflecting on those experiences. But we also wanted to utilise methods which brought learning into $21^{\text {st }}$ century thinking. Connectivism places emphasis on the importance of encouraging students to search for, filter, analyse and synthesise information in order to obtain knowledge. Some of connectivism's principles are [22]:

- Learning and knowledge rests in diversity of opinions.

- Learning is a process of connecting specialized information sources.

- Learning may reside in non-human appliances (technology).

- Nurturing and maintaining connections is needed to facilitate continual learning.

- The ability to see connections between fields, ideas, and concepts is a core skill.

In the following section, we describe the methods and experiences involved in the development of the above mentioned learning tools. Each partner country was required to produce one tool for each topic area, leading to the development of eighteen tools in total.

The methodology for creating the learning/teaching tools described here, was prepared by Professor Irena Papadopoulos - the project coordinator - who provided the following guidance for their development and a template to facilitate the application of the guidance.

\section{What do we mean by 'tools'?}

Learning tools are 'materials' which students use on their own or with others to learn about a topic, to develop their cognitive (thinking), psychomotor (practical) and affective 
(emotional) competencies. Learning tools may be identified or developed by the students or the teachers (sometimes referred to as teaching tools). Because every individual learns in a different way, teachers use a variety of learning/ teaching tools, to respond to the diversity of learning styles. For example, tools could be a book, a picture, a power point presentation, a diagram, a quiz, a visit, a podcast, a song, a video, a computer game, a website and so on.

\section{What does a good tool look like}

The following list can be used as a checklist for learning/ teaching tools. Not all learning tools will meet all criteria. But generally speaking the more criteria a learning tool meets, the stronger the tool.

A good tool:

- Contains customised steps to help students progress through their learning goals;

- Provides observable evidence of learning;

- Clarifies what students know and don't know;

- Allows the teacher to see/hear (and intervene) when students don't understand;

- Leads to and connects with other tools in the process of meeting larger/ /higher level learning goals;

- Helps students synthesize knowledge and meaning;

- Provides building blocks that enable students to step into and through difficult concepts or processes to reach predetermined learning goals;

- Provides pathways that lead to depth and clarity in learning;

- Adds to the meaning-making in the classroom.

(Modified from a list provided by the Perpich Center for Arts Education http://www.mnartseducation.org/docs/03/ _pdf/03_01.pdf)

\section{Guiding values}

Taken from the United Nations human rights declaration, the overall guiding value of our methodology is:

'All human beings are born free and equal in dignity and rights. They are endowed with reason and conscience and should act towards one another in a spirit of brotherhood'.

(http://www.un.org/cyberschoolbus/humanrights/declaration/1.asp)

Specific values of the IENE 3 team were identified via a values workshop which used 'compassion' as the vehicle for the value clarification exercise at the beginning of the project. The values identified were compatible to those included in the 'Effective Values Education' (See Table 1).
In addition to the above, we aspired to the following specific values of intercultural education we identified and synthesized from the literature (See Table 2).

\section{Guiding Principles for structuring the tools}

The principles which informed the methodology utilized for the development of the IENE3 tools derive from the previous work on the Papadopoulos, Tilki and Taylor (PTT) model of transcultural nursing and cultural competence $[13,23]$. They were further informed by the Intercultural Education of Nurses in Europe - IENE1 \& IENE2 projects. These two informing structures are described as follows:

\section{a) The PTT Model}

The PTT model of transcultural nursing and cultural competence consists of four constructs: 'cultural awareness', 'cultural knowledge', and 'cultural sensitivity', leading to the achievement of the fourth construct 'cultural competence'. Each of the four constructs is briefly defined in Table 3:

\section{b) IENE1 and IENE2 Projects}

As part of the Leonardo Partnership project "IENE 1", participating partners adapted the Papadopoulos, Tilki and Taylor (PTT) (1998) model to reflect the needs of nurses in their countries following a needs assessment exercise. This PTT/IENE model was used as a learning guide map (http://www.ieneproject.eu/learning.php) to develop learning units which are freely available on the IENE website (http://www.ieneproject.eu/). An extensive glossary, an informative learning guide, outlines of learning units with learning materials, the learning tools (covering compassion, courage, intercultural communication) and much more are available on open access to nurses and other healthcare professionals. During IENE2 this

Table 1 Effective 'values education'

- helps students to understand and to be able to apply valuessuch as care and compassion;

- pursues excellence by requiring the students to do their best;

- purses and protects the common good where all people are treated fairly for a just society;

- pursues freedom in order to protect the rights of self and others;

- pursues honesty and truth;

- helps the students achieve consistency between their words and deeds in accordance with moral and ethical conduct;

- promotes the respectful treatment of others;

- promotes personal responsibility and accountability of one's own actions and the resolve of differences in a non-violent and peaceful ways;

- promotes the understanding and tolerance of others and their cultures, the acceptance of diversity and the inclusion of others.

Adapted from: National Framework for Values Education in Australian Schools, DEST 2005, p 5, http://www.curriculum.edu.au/verve/_resources/

framework_pdf_version_for_the_web.pdf 
Table 2 Values of intercultural education as identified and synthesized from the literature

- Respecting the cultural background and identity of the learner by relating learning to their previous knowledge and experiences - Providing equal access to learning by eliminating discrimination in the education system and by promoting an inclusive learning environment - Promoting learning which encourages the understanding of personal values and the development of self -awareness, both of which form the basis for reflective communication and co-operation across cultures and social boundaries

- Promoting a critical approach regarding the power linked to the production and use of knowledge to either oppress or emancipate people

- Tolerating language imperfections by providing language support and/ or by allowing extra time for people to express themselves

- Avoid over-dependence on oral learning methods and use visual and other interactive and culturally appropriate learning approaches - Emphasising realism. Intercultural learning is a life long process - Promoting courage. Thinking outside the box and speaking out against injustice.

innovative model was adapted and integrated into the transcultural education of nurses and healthcare professionals in four partner countries: Belgium, Germany, Romania and France.

An important element for the creation of the learning tools was innovation (see Fig. 1).

Table 3 Brief definition of the four constructs of the PTT model Cultural Awareness

The degree of awareness we have about our own cultural background and cultural identity. This helps us to understand the importance of our cultural heritage and that of others, and makes us appreciate the dangers of ethnocentricity.

Cultural Knowledge

Derives from a number of disciplines such as anthropology, sociology, psychology, biology, nursing, medicine, and the arts, and can be gained in a number of ways. Meaningful contact with people from different ethnic groups can enhance knowledge around their health beliefs and behaviours as well as raise understanding around the problems they face.

\section{Cultural Sensitivity}

This entails the crucial development of appropriate interpersonal relationships with our clients. An important element in achieving cultural sensitivity is how professionals view people in their care. Unless clients are considered as true partners, culturally sensitive care is not being achieved.

\section{Cultural Competence}

The capacity to provide effective healthcare taking into consideration people's cultural beliefs, behaviours and needs. Cultural competence is both a process and an output, and results from the synthesis of knowledge and skills which we acquire during our personal and professional lives and to which we are constantly adding.

This model combines both the multi-culturalist and the anti- racist perspectives and facilitates the development of a broader understanding around inequalities, human and citizenship rights, whilst promoting the development of skills needed to bring about change at the patient/client level.

(http://www.ieneproject.eu/glossary.php)
The model for the development of IENE3 tools to promote culturally competent and compassionate healthcare

As illustrated in Fig. 2, the proposed model utilises the construct of 'compassion' in the application of the overall methodology for the development of tools. Each topic under development (compassion, courage, intercultural communication) is placed in the centre of the four boxes which contain the main constructs of the PTT/IENE model. In each of the four boxes a small number of subconstructs are proposed, related to the learning tool under development (Fig. 2 applies the development principles for the 'compassion' tool). In this way each sub-construct is considered not only for its own sake but, importantly, it is also considered from the cultural perspective. For example, in order to begin the process of becoming a culturally competent and compassionate health professional, a student should be encouraged to reflect on the meaning, understanding, and expressions of compassion from their own cultural point of view.

By replacing 'compassion' with 'courage' in the centre of the diagram, we can identify relevant sub-constructs for 'courage' and then develop the learning tool, around these sub-constructs. We then repeat this process for 'intercultural communication'.

\section{The components of the IENE3 learning tools}

Four main components were identified for inclusion in the development of the IENE3 learning tools (see Fig. 3). These are:

- the theoretical component

- the practical component

- the assessment component

- the evaluation component

Participating countries were provided with a template for the development of the tools (see Table 4):

A practical summary of the procedures and steps involved in the application of the IENE 3 tool methodology is outlined in Fig. 4.

\section{The Tools}

Each participating country developed their own set of tools utilizing the methodology, components and template described above. There were differences between countries regarding the content of the tools and in terms of assessment and activities, but all had followed the same methodology and structure. The final versions of the IENE3 tools consisted of an interesting array of literature, underpinning values, and both theoretical and practical activities. Whilst it is beyond the scope of this paper to describe in detail each of the tools, below we provide example content from the UK compassion tool. 


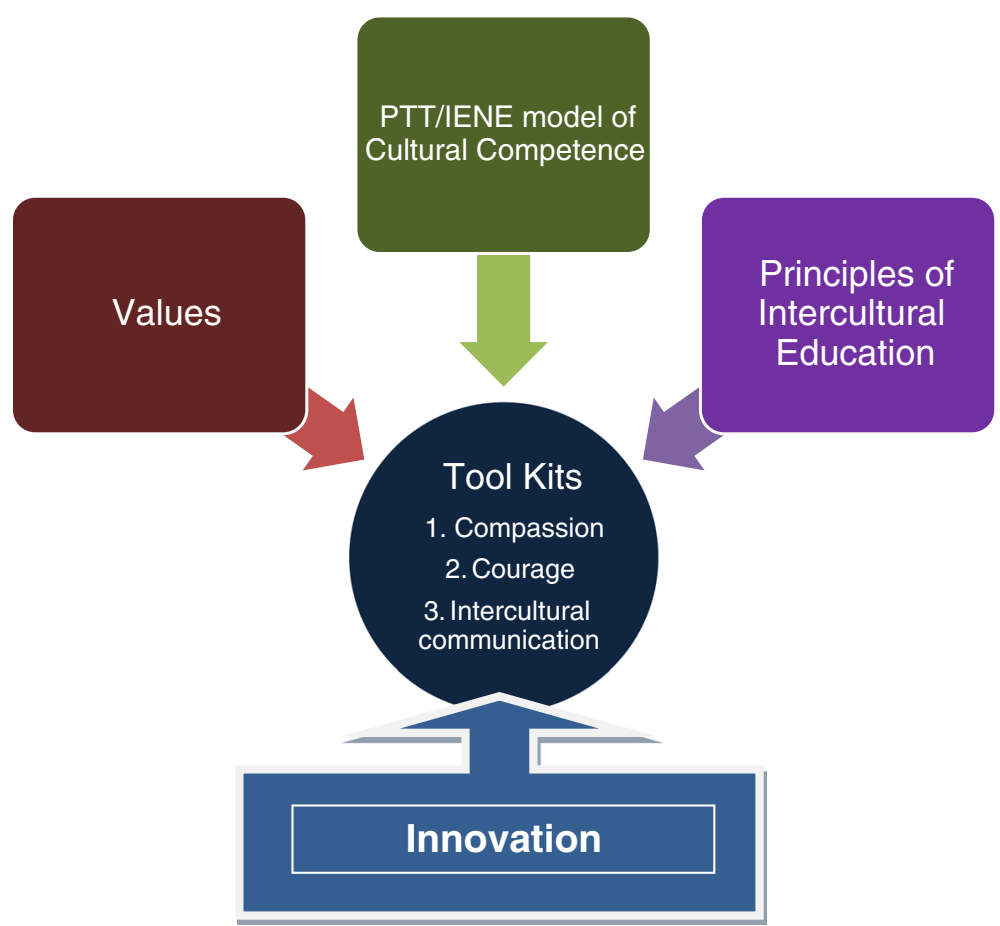

Fig. 1 A visual representation of the key elements required for the development of the learning tools

The complete tools can be accessed at http://tinyurl.com/njs2bxm

Middlesex University, UK, Compassion Tool

Example (a) - Theoretical Component Principles and Values
The principles underpinning the tool included the following:

- Shared learning

- Valuing experience

- Building on what is already known

- Equality of access

- Exploring similarities and differences

\section{THE PAPADOPOULOS MODEL FOR DEVELOPING CULTURALLY COMPETENT AND COMPASSIONATE HEALTHCARE PROFESSIONALS}

\section{Cultural Awareness}

-Self-compassion

-Universal elements of

compassion

- Philosophies and religions

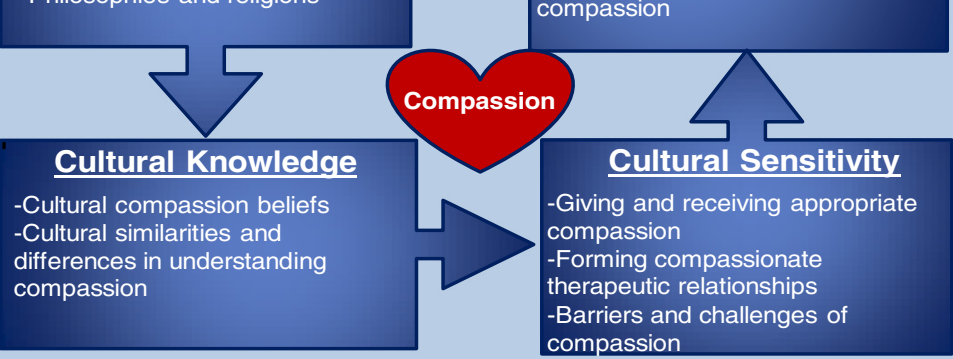

(C) Irena Papadopoulos 2014

Fig. 2 The Papadopoulos model for developing culturally competent and compassionate healthcare professionals 


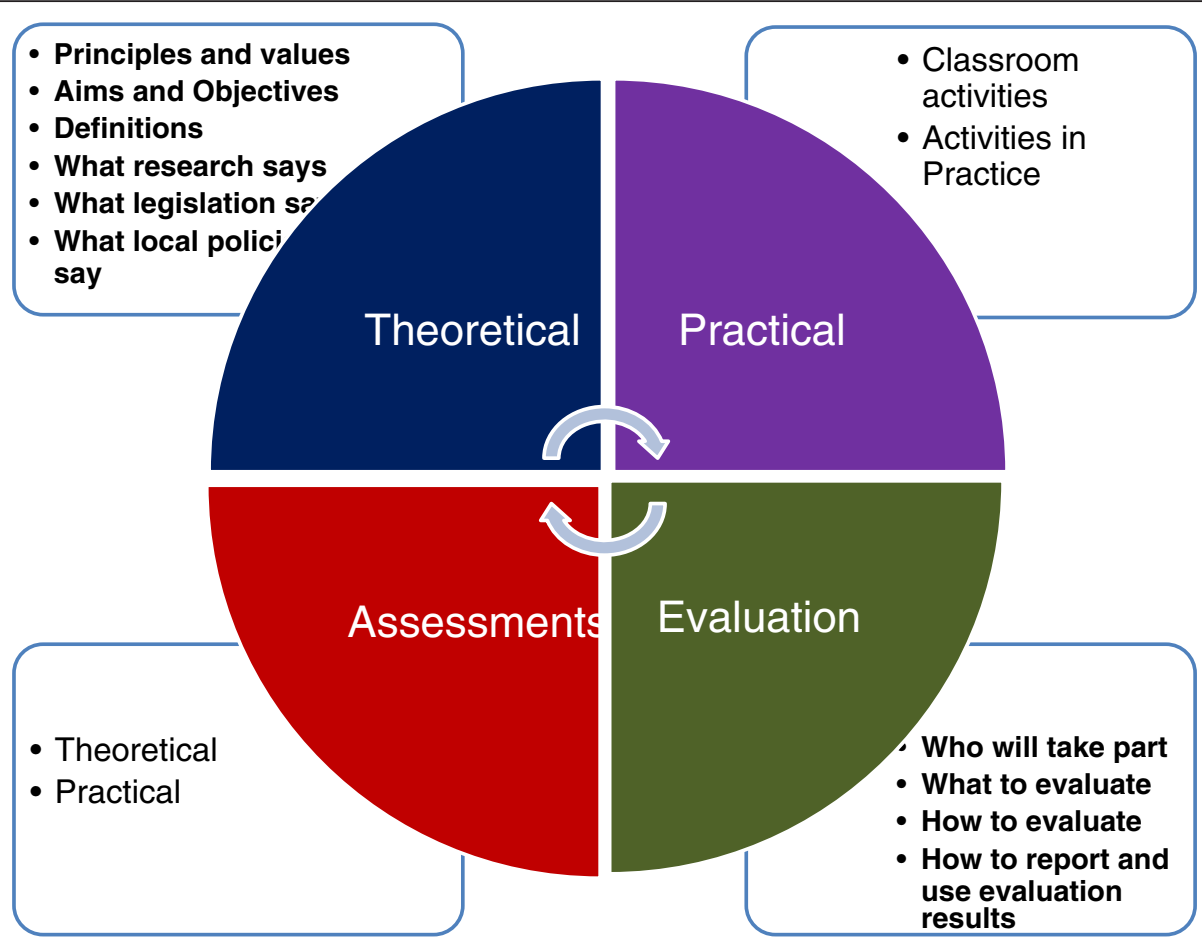

Fig. 3 Components of a too

- Tolerance

- Fostering curiosity

- A commitment to life-long learning

The tool is informed by the following values:

- Respect

- Dignity

- Equity

- Human rights

- Acceptance

- Inclusion

Table 4 Template for development of the tool

a) Theoretical aspects of the tool (please use as much space as needed:

Title; principles and values relevant to the tool; overall aim for the tool; learning outcomes; relevant definitions and terms; what the research says on the topic; what the legislation/treaties/conventions say on the topic; what local policies say.

b) Practical aspects of the tool:

Classroom activities; activities in Practice.

c) Tool assessment:

Theoretical assessment; practical assessment.

d) Evaluation

The common one (compulsory) and specific one designed by you (optional).

e) Authorship:

Names of people who led the development
- Empathy

- Professionalism

Example (b) - Practical Components Examples of some of the activities included are as follows:

1. Think about a time when you were suffering in some way, maybe you were stressed about something. Was someone kind to you? Did someone convey compassion for you? How did you feel? Make some notes about what helped you to feel better. What would be your own personal definition of compassion?

2. Access and read the following article in order to enhance your knowledge and understanding of compassion:

Staughair, C. (2012) Exploring compassion; implications for contemporary nursing.Part 1. British Journal of Nursing, 21(3): 160-164

3. We know that compassion involves interpersonal skills. Compassionate communication includes respect for, and interest in, patient experience (Price, 2013). This means being sensitive to the patient experience. It will also entail making adjustments to meet the needs of your individual patients.

Ask patients what they found helpful. Record your findings in your reflective diary. What are the similarities and differences in your individual patients' responses? Make two lists - one of the similarities and 


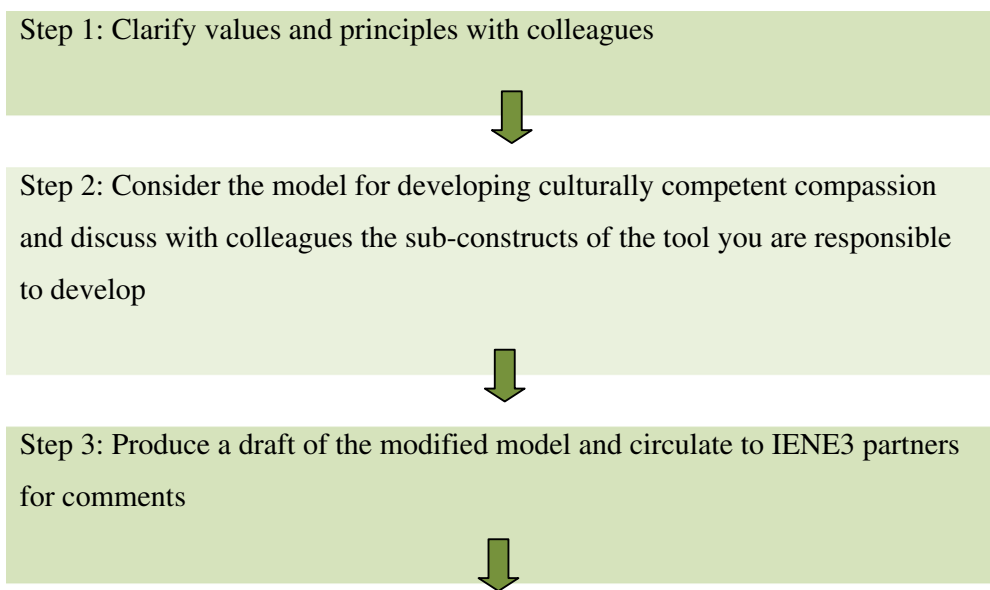

Step 4: Adjust model according to comments.

Finalise and issue to colleagues and partners
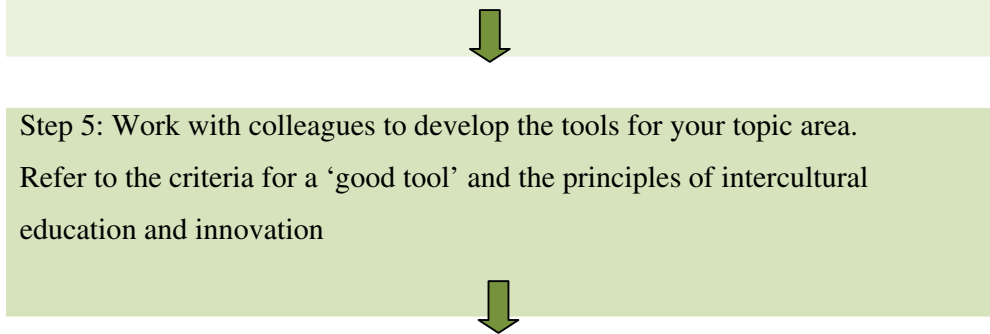

Step 6: Use the template to document details of your tool/s

Include instructions for teachers

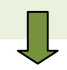

Step 7: Circulate to partners

Fig. 4 The seven steps of the IENE 3 tool methodology

one of the differences. How will you adjust your practice as a result of what your patients are telling you?

4. During your nursing practice, identify a role model - a nurse about whom you can say 'That is the sort of nurse I want to become'.

What is it about this nurse's practice that you admire? What does he or she do that has inspired you?

How does he or she relate to patients, convey compassion, ensure care is safe and effective? How would you describe his or her professional values?

\section{Ethics}

The IENE3 programme received ethical approval by Middlesex University. There are no ethical issues in terms of harm, exploitation, confidentiality, inequalities etc. Student participants were given information about the project and asked to participate in a session and complete an anonymous questionnaire. They were given the choice not to participate.

\section{Results}

Although each participating country followed the same methodology and structure, there were certain differences between countries, with regard to content, activities and assessment thus ensuring their cultural relevance.

Activities were innovative and thought provoking utilizing presentations, games, songs, pictures, reading, videos, role-play, discussion, brainstorming, and opportunities for reflective learning. Furthermore, a number of case studies were included in the tool-kits, which focused on multicultural needs and aimed to promote the synthesis of learning 
about compassion, courage and intercultural communication, leading to a positive learning experience.

Following the piloting of the tools with student nurses, some very positive feedback was received including the following:

The enthusiasm of the teacher and the tool itself really helped me to grab the subject

Very nice and creative lesson. It really helps to teach about cultural issues. Clear explanation

It was wonderful to see how compassion care affected the pupils.

Learned a lot and I can really use it in my daily practice

It was enlightening...every nurse can learn from this.. An eye opener to use this way to ask questions, without prejudices. Very instructive, I can use this in my daily practice

With regard to evaluation of the tools, the majority of responses indicated that the learning criteria had been fully met for each of the three tools, across all six participating countries.

\section{Discussion}

Within this paper, we have discussed the importance of care delivery which is both compassionate and culturally competent in its approach. We have outlined the procedure involved in the development of three learning tools to support and train nurses and other healthcare professionals on the important issues of compassion, courage, and intercultural communication. The IENE3 tools aim to increase sensitivity in those working within multicultural societies. Through the development of the IENE3 learning tools, a range of activities were developed.

The learning tools developed as part of this project enable students to become stimulated and to engage in autonomous and co-operative learning. Students felt that the tools promoted non-judgemental and non-discriminatory thinking and enjoyed being involved in immersive collaborative learning. They further felt that the tools helped them to develop the cultural aspects of compassion and communication.

The feedback received from the students provides evidence with regards to the effectiveness of the tools, and can help us to advance in the training of culturally competent and compassionate care providers. This may lead to increased quality of care for vulnerable individuals, better health outcomes and enhanced job satisfaction for nurses and other healthcare professionals.

The PTT/IENE model provided a framework, around which each participating country could utilize cultural sub-constructs within the context of their own country.
Learning to be culturally competent in a compassionate manner is crucial in order to develop the necessary integrative skills and understanding for crossing boundaries in healthcare. Such an approach can assist nurses in becoming more culturally competent, which is crucial to those working in multicultural societies. Furthermore, learning tools such as these can help to overcome the issue of health inequalities and may lead to greater cost effectiveness.

When working and residing within multicultural societies, an understanding of cultural diversity and the needs and values of others is essential. The development of the tools referred to in this paper, has led to a thought provoking experience, not just for the students, but also for the tool developers in terms of reflecting on how best to train nurses to deliver culturally competent and compassionate care.

\section{Limitations and implications}

A potential limitation of this study is that the tools were piloted mainly with student nurses only. However, in the future the tools could equally provide an important learning experience for other healthcare professionals. A further benefit of the tools lies in the flexibility of their content, meaning that their elements could be extended over time, or included in short courses, modules or workshops. With the foundation knowledge acquired through the use of these tools, students can extend and apply this knowledge, making it specific to their own work. All tools are available on-line (http://www.ieneproject.eu/).

\section{Conclusion}

The development of new learning methods arises from the need to be compassionate towards patients, to have the courage to report bad practice and to communicate competently at an intercultural level. With the help of learning tools that provide practical activities and case scenarios based on real life experiences, we hope that students will acquire and practice skills of compassion, courage, and intercultural communication within the multicultural health care setting.

The tools allow for reflection of good practice, and work is in place to further implement the tools and evaluate the longer term effects among healthcare professionals and service user health outcomes. A further project, referred to as IENE4 is currently under way to develop a European model of learning that will enable nurses and other health professional leaders to develop their mentorship role in order to help staff deliver culturally competent and compassionate care and promote a compassionate environment culture. 


\section{Competing interests}

The authors declare they have no competing interests.

\section{Authors' contributions}

IP conceived the study, designed, authored the guidelines and templates for the development of the tool, co-authored the tool which this article is based on, participated in the data analysis and interpretation, guided the drafting of the article and revised it critically for important intellectual content. SS contributed in the drafting of the article and helped to revise it critically for important intellectual content. GT co-authored the tool which this article is based on. AP helped in the drafting of the article and the data collection. LF Piloted the tool and collected the data. All authors read and approved the final manuscript.

\section{Acknowledgements}

We wish to thank the following partners for their participation in this study: Victor Dudau, Lucia Babu, Pusa Barbulescu, Mihai Pistol, EDUNET Organization, Romania

Annemiek van Workum, Marga Hop, Joyce van Dijk, ROC Albeda College, Netherlands

Friederike Jung, René Hildebrandt, Karin Senf, Volkssolidarität Gera, Germany Claudia Rustici, Antonella Gorelli, Maurilio Pallassini, Maria Luisa Verzuri, Norvegia Belardinelli, Monica Bianchi, Lore Lorenzi, Anna Coluccia, Cristina Masoni, Azienda Ospedaliera Universitaria Senese, Italy

Serpil Tural, Marmara University Research and Training Hospital, Turkey Although the above named were not involved in the development and piloting of the specific tool discussed in this article, they were all involved in the wider project (Intercultural Education of Nurses in Europe 3) in which the development of this and two other tools was located.

\section{Funding details}

This projects described in this article have been funded by the European Commission's Lifelong Learning Programme.

\section{Received: 17 October 2015 Accepted: 9 February 2016}

\section{Published online: 19 February 2016}

\section{References}

1. Youngson R. Time to care: how to love your patients and your job. New Zealand: Rebelheart Publishers; 2012.

2. Shea S, Wynyard R, Lionis C, editors. Providing compassionate healthcare: challenges in policy and practice. Oxon and New York: Routledge; 2014.

3. Francis R. QC. Report of the mid staffordshire NHS foundation trust public inquiry, house of commons. London: Stationery office (Vols 1-3); 2013.

4. Schantz ML. Compassion: A concept analysis. Nurs Forum. 2007;42(2):48-55.

5. Goetz JL, Keltner D, Simon-Thomas E. Compassion: An evolutionary analysis and empirical review. Psychol Bull. 2010;136(3):351-74.

6. Fogarty LA, Curbow BA, Wingard JR, McDonnell K, Summerfield MR. Can 40 seconds of compassion reduce patient anxiety? J Clin Oncol. 1999;17(1):371.

7. Shaltout HA, Toozer JA, Rosenberger MA, Kemper KJ. Time, touch, and compassion: effects on autonomic nervous system and well-being. Explore. 2012;8(3):177-84

8. Science daily website. http://www.sciencedaily.com. Accessed January 2015.

9. Cole-King A, Gilbert P. Compassionate care: the theory and the reality. In: Shea S, Wynyard R, Lionis C, editors. Providing compassionate health care challenges in policy and practice. Oxon and New York: Routledge; 2014.

10. Bach S, and Grant A. Communication \& interpersonal skills for nurses. Exeter: Learning Matters. 2009.

11. Etowa JB, Foster S, Vukic AR, Wittstock W, Youden S. Recruitment and retention of minority students: diversity in nursing education. Int J Nurs Educ Scholarsh. 2005;2(1):1548-923X.

12. Lehman et al. Diversity and cultural competency in health care settings (http://www.matherlifewaysinstituteonaging.com/wp-content/uploads/2012/ 03/diversity-and-cultural-competency-in-health-care-settings.pdf (Accessed 15 July 2015)).

13. Papadopoulos I, editor. Transcultural health and social care: development of culturally competent practitioners. Edinburgh: Churchill Livingstone Elseviers; 2006

14. Department of Health UK. The NHS constitution: The NHS belongs to us all, 2015. (https://www.gov.uk/government/publications/the-nhs-constitution-forengland/the-nhs-constitution-for-england).
15. European Commission. Quality in and equality of access to healthcare services, 2008. (http://www.euro.centre.org/data/1237457784_41597.pdf).

16. Papadopoulos I. Courage, compassion and cultural competence. The 13th anna reynvaan lecture. Netherlands: De Stadsschouwburg - Amsterdam City Theatre; 2011.

17. Papadopoulos I, Pezella A. A snapshot review of culturally competent compassion as addressed in selected mental health textbooks for undergraduate nursing students. J Compassionate Health Care. 2015;2(3). http://jcompassionatehc.biomedcentral.com/articles/10.1186/s40639-0150012-5.

18. Pence GE. Can compassion be taught? J Med Ethics. 1983:9:189-91.

19. Hughes $\mathrm{KH}$, Hood LJ. Teaching methods and an outcome tool for measuring cultural sensitivity in undergraduate nursing students. J Transcult Nurs. 2007;18(1):62.

20. Bruner J. The process of education. Cambridge MA: Harvard University Press; 1960

21. Vygotsky LS. Mind in society: the development of higher mental processes. Cambridge MA: Harvard University Press; 1978.

22. Siemens G. Connectivism: a learning theory for the digital age. 2004. http://www.elearnspace.org/Articles/connectivism.htm. (Accessed September 2015).

23. Papadopoulos I, Tilki M, Taylor G. Transcultural care: a guide for health care professionals. Wilts: Quay Books; 1998. ISBN 1-85642-051 5.

\section{Submit your next manuscript to BioMed Central} and we will help you at every step:

- We accept pre-submission inquiries

- Our selector tool helps you to find the most relevant journal

- We provide round the clock customer support

- Convenient online submission

- Thorough peer review

- Inclusion in PubMed and all major indexing services

- Maximum visibility for your research

Submit your manuscript at www.biomedcentral.com/submit
BioMed Central 